\title{
Analisis Relevansi Nilai PSAK No. 30 (Revisi 2007) tentang Sewa, Dinilai Berdasarkan Reaksi Pasar Modal
}

\author{
Dewi Kartika Sari ${ }^{1 *}$ \\ ${ }^{1}$ Program Studi Akuntansi Program Vokasi Universitas Indonesia
}

\begin{abstract}
ABSTRAK. Sebagai salah satu program konvergensi IFRS, DSAK-IAI telah melakukan beberapa revisi standar akuntansi keuangan, salah satunya adalah PSAK No. 30 (Revisi 2007) tentang Sewa. Standar keuangan ini telah mulai efektif sejak tanggal 1 Januari 2008. Namun sampai saat ini masih sedikit perusahaan yang menerapkannya. Hal tersebut mungkin disebabkan karena perusahaan belum mengetahui manfaat dari penerapan standar keuangan ini. Oleh karenanya penelitian ini dilakukan untuk mengetahui relevansi nilai dari PSAK No. 30 (Revisi 2007) tentang Sewa, yang dinilai berdasarkan reaksi pasar modal.
\end{abstract}

Hasil penelitian menunjukkan bahwa penerapan PSAK No. 30 (Revisi 2007) tentang Sewa, tidak memiliki pengaruh terhadap pasar. Sehingga dapat dikatakan pasar tidak melihat relevansi nilai dari PSAK No. 30 (Revisi 2007) tentang Sewa ini.

Kata kunci: Relevansi nilai, PSAK No. 30 (Revisi 2007) tentang Sewa.

ABSTRACT. As one of the IFRS convergence program, DSAK-IAI has made several revisions of financial accounting standards, one of which is PSAK No. 30 (Revisi 2007) about Leases. These financial accounting standards have become effective since January 1, 2008. But until now still a ferw companies that apply this standard. This is probably because the company did not know the financialbenefitofthe application ofthisstandard. Thereforethis studywas conducted to determinethe value relevance of PSAK No.3O (Revised 2007) about Leases, which is assessed on the basis of capital market reactions.

The results showedthat theapplication of PSAK No.30 (Revised 2007), about Leases, do nothave an influence onthe market. So we can saythe market does notsee thevalue relevance of PSAK No.3o (Revised 2007) about Leases.

Key words: Value relevance, PSAK No. 30 (Revisi 2007) about Leases.

\section{PENDAHULUAN}

\subsection{Latar Belakang Penelitian}

Sampai saat ini, IFRS (International Financial Reporting Standard) telah digunakan lebih dari 100 negara. Para negara yang tergabung dalam G-20 juga telah menyepakati adanya komitmen bersama untuk menggunakan satu standar akuntansi yang diterapkan secara global. Oleh karenanya, guna mewujudkan komitmen Indonesia sebagai anggota 
IFAC dan anggota negara G20, maka sejak tahun 2007 Dewan Standar Akuntansi Keuangan (DSAK) IAI telah melakukan program konvergensi IFRS (Sinaga, 2009). Salah satu standar akuntansi yang terkena efek dari program konvergensi IFRS ini adalah standar akuntansi keuangan mengenai sewa (PSAK No. 30 - revisi 2007).

Efektif tanggal 1 Januari 2008, PSAK No. 30 (Revisi 2007), "Sewa” menggantikan PSAK No. 30 (1990) "Akuntansi Sewa Guna Usaha”. Berdasarkan PSAK No. 30 (Revisi 2007), suatu sewa diklasifikasikan sebagai sewa pembiayaan jika terdapat pengalihan risiko dan manfaat yang substansial atas aset sewa dari lessor ke lessee. Jika tidak ada pengalihan risiko dan manfaat yang substansial maka transaksi sewa akan diklasifikasikan sebagai sewa operasi. PSAK No. 30 (Revisi 2007) ini merupakan adopsi dari IAS No. 17 (2003).

Walau PSAK No. 30 (Revisi 2007) ini telah berlaku efektif sejak tanggal 1 Januari 2008, namun masih sedikit perusahaan yang menerapkannya (Wihardja, 2009). Hal ini sangat disayangkan, padahal menurut Wihardja (2009) penerapan standar ini dapat memicu arus investasi global ke Indonesia, transparansi dan akuntabilitas perusahaan akan jelas terlihat. Ke depannya tidak akan ada lagi aset dan kewajiban (yang timbul dari perjanjian sewa atau mengandung sewa) yang bersifat off-balance sheet, perusahaan tidak lagi bisa menyembunyikan hutang terkait yang mengandung sewa perjanjian.

Baru sedikitnya perusahaan yang menerapkan standar ini mungkin disebabkan karena perusahaan belum tahu adanya revisi atas PSAK No. 30 ini (sosialisasi standar yang kurang), atau perusahaan belum mengetahui manfaat dari penerapan standar ini sehingga mereka enggan untuk menerapkannya (Wihardja, 2009). Atau bahkan mungkin standar akuntansi ini tidak memiliki kandungan informasi lebih dibandingkan standar akuntansi mengenai sewa sebelumnya, sehingga masih banyak perusahaan yang tidak menerapkannya.

Di luar negeri penelitian tentang sewa telah banyak dilakukan, antara lain penelitian yang dilakukan oleh Jamal dan Tan (2009), Tsakumis, Doupnik, dan Agoglia (2009). Sedangkan penelitian mengenai relevansi nilai dari suatu standar akuntansi keuangan telah dilakukan oleh Cheng, Liu, dan Schaefer (1997), dan Cheng dan Hsieh (2000). Di Indonesia, sepanjang pengetahuan penulis masih sangat sedikit penelitian yang mengkaji mengenai sewa. Penelitian mengenai sewa yang telah dilakukan di Indonesia antara lain dilakukan oleh Nursasmito dan Sumiyana (2008) yang 
melakukan pengujian atas efektivitas penerapan kriteria sewaguna kapital yang diunjukkan oleh PSAK No. 30 (Akuntansi Sewaguna Usaha). Sampai saat ini peneliti belum menemukan penelitian terkait dengan relevansi nilai suatu standar akuntansi keuangan

Oleh karenanya guna merespon masalah di atas, maka penelitian ini ingin menguji bagaimana relevansi nilai dari penerapan PSAK No. 30 (Revisi 2007) dilihat dari bagaimana pasar modal bereaksi.

\subsection{Masalah Penelitian}

Dengan latar belakang yang telah dijelaskan sebelumnya, maka permasalahan dalam penelitian ini adalah untuk memberikan bukti empiris di Indonesia mengenai:

- Apakah PSAK No. 30 (Revisi 2007) tentang sewa, memiliki relevansi nilai?

\subsection{Tujuan Penelitian}

Tujuan penelitian ini adalah untuk memberikan bukti empiris di Indonesia mengenai:

- Relevansi nilai dari PSAK No. 30 (Revisi 2007) tentang sewa.

1.4 Manfaat Penelitian

a. Manfaat Akademik
Penelitian ini diharapkan dapat memberi tambahan literatur mengenai relevansi nilai dari suatu standar akuntansi keuangan.

\section{b. Manfaat Praktisi}

\section{- Bagi IAI}

Penelitian ini merupakan salah satu pendokumentasian adanya penerbitan standar akuntansi keuangan baru. Dengan adanya penelitian ini diharapkan dapat memberikan gambaran kepada IAI bagaimana pasar bereaksi terhadap standar yang dikeluarkan.

\section{- Bagi analis keuangan dan investor}

Hasil dari penelitian ini diharapkan dapat memberi tambahan petunjuk atau sinyal dalam memilih investasi yang baik.

\section{- Bagi perusahaan}

Diharapkan dengan adanya penelitian ini perusahaan dapat melihat keuntungan dari diterapkannya PSAK No. 30 (Revisi 2007), sehingga kemudian terdorong untuk menerapkan standar ini. PERUMUSAN HIPOTESIS 
2.1. Standar Akuntansi Keuangan No. 30 tentang Sewa (PSAK No. 30 Revisi 2007)

PSAK No. 30 (Revisi 2007) tentang SEWA ini telah disahkan oleh Dewan Standar Akuntansi Keuangan (DSAK) pada tanggal 27 Juni 2007, menggantikan PSAK 30 tentang SEWA GUNA USAHA yang telah dikeluarkan DSAK sejak 7 September 2004 (IAI, 2009).

Pernyataan ini bertujuan untuk mengatur kebijakan akuntansi dan pengungkapan yang sesuai, baik bagi lessee maupun lessor dalam hubungannya dengan sewa (lease). Pernyataan ini diterapkan dalam akuntansi untuk semua jenis sewa selain: (a) sewa dalam rangka eksplorasi atau penambangan mineral, minyak, gas alam dan sumber daya lainnya yang tidak dapat diperbarui; dan (b) perjanjian lisensi untuk hal-hal seperti film, rekaman video, karya panggung, manuskrip (karya tulis), hak paten dan hak cipta. Namun demikian, Pernyataan ini tidak diterapkan sebagai dasar pengukuran untuk: (a) properti yang dikuasai oleh lessee yang dicatat sebagai property investasi (PSAK 13); (b) properti investasi yang diserahkan oleh lessor yang dicatat sebagai sewa operasi (PSAK 13); (c) aset biologis yang dikuasai oleh lessee yang dicatat sebagai sewa pembiayaan; atau (d) aset biologis yang diserahkan oleh lessor yang dicatat sebagai sewa operasi.

Beberapa perbedaan antara PSAK No. 30 (Revisi 2007) dengan PSAK No. 30 (1990) dapat dilihat dalam tabel (2.1) di bawah ini:

Tabel 2.1.

Perbedaan PSAK No. 30 (Revisi 2007) Dengan PSAK No. 30 (1990)

\begin{tabular}{|c|c|c|}
\hline Keterangan & PSAK No. 30 (Revisi 2007) & PSAK No. 30 (1990) \\
\hline Definisi Sewa & $\begin{array}{l}\text { Sewa adalah suatu perjanjian dimana } \\
\text { lessor memberikan hak kepada lessee } \\
\text { untuk menggunakan suatu aset selama } \\
\text { periode waktu yang disepakati. Sebagai } \\
\text { imbalannya, lessee melakukan } \\
\text { pembayaran atau serangkaian } \\
\text { pembayaran kepada lessor. }\end{array}$ & $\begin{array}{l}\text { Sewa adalah setiap kegiatan pembiayaan yang } \\
\text { dilakukan oleh badan usaha dalam rangka } \\
\text { penyediaan barang modal, baik secara Finance } \\
\text { Lease maupun Operating Lease untuk } \\
\text { digunakan oleh Penyewa Guna Usaha selama } \\
\text { jangka waktu tertentu berdasarkan } \\
\text { pembayaran secara berkala }\end{array}$ \\
\hline $\begin{array}{l}\text { Awal sewa } \\
\text { (inception of the } \\
\text { lease) vs Awal } \\
\text { masa sewa } \\
\text { (commencement } \\
\text { of the lease } \\
\text { term) }\end{array}$ & $\begin{array}{l}\text { Awal sewa (inception of the lease), } \\
\text { adalah tanggal yang lebih awal antara } \\
\text { tanggal perjanjian sewa dan tanggal- } \\
\text { tanggal pihak-pihak menyatakan } \\
\text { komitmen terhadap ketentuan- } \\
\text { ketentuan pokok sewa. } \\
\text { Awal masa sewa (commencement of } \\
\text { the lease term), adalah tanggal saat }\end{array}$ & $\begin{array}{l}\text { Tidak ada panduan yang jelas antara awal } \\
\text { sewa dengan awal masa sewa. }\end{array}$ \\
\hline
\end{tabular}




\begin{tabular}{|c|c|c|}
\hline Keterangan & PSAK No. 30 (Revisi 2007) & PSAK No. 30 (1990) \\
\hline & $\begin{array}{l}\text { lessee mulai berhak untuk menggunakan } \\
\text { aset sewaan. Tanggal ini merupakan } \\
\text { tanggal pertama kali sewa diakui (yaitu } \\
\text { pengakuan aset, kewajiban, penghasilan } \\
\text { atau beban sewa) }\end{array}$ & \\
\hline \multirow{3}{*}{$\begin{array}{l}\text { Klasifikasi } \\
\text { Sewa }\end{array}$} & Sewa $=$ Sewa & Sewa $=$ Sewa Guna Usaha \\
\hline & $\begin{array}{l}\text { Sewa pembiayaan (finance lease) adalah } \\
\text { sewa yang mengalihkan secara } \\
\text { substansial seluruh risiko dan manfaat } \\
\text { yang terkait dengan kepemilikan suatu } \\
\text { aset. Hak milik pada akhirnya dapat } \\
\text { dialihkan, dapat juga tidak dialihkan. }\end{array}$ & $\begin{array}{l}\text { Sewa Guna Usaha Pembiayaan (finance lease) } \\
\text { adalah jenis sewa jika memenuhi kriteria } \\
\text { berikut: } \\
\text { - } \quad \text { Penyewa guna usaha memiliki hak opsi } \\
\text { untuk membeli aktiva yang } \\
\text { disewagunausahakan pada akhir masa sewa } \\
\text { guna usaha dengan harga yang telah } \\
\text { disetujui bersama pada saat dimulainya } \\
\text { perjanjian sewa guna usaha; } \\
\text { - Seluruh pembayaran berkala yang } \\
\text { dilakukan oleh penyewa guna usaha } \\
\text { ditambah dengan nilai sisa mencakup } \\
\text { pengembalian harga perolehan barang } \\
\text { modal yang disewagunakan serta } \\
\text { bunganya, sebagai keuntungan perusahaan } \\
\text { sewa guna usaha (full payout lease); } \\
\text { Masa sewa guna usaha minimum } 2 \text { (dua) } \\
\text { tahun. }\end{array}$ \\
\hline & $\begin{array}{l}\text { Sewa operasi (operating lease) adalah } \\
\text { sewa selain sewa pembiayaan }\end{array}$ & $\begin{array}{l}\text { Jika salah satu kriteria di atas tidak terpenuhi } \\
\text { maka transaksi sewa guna usaha } \\
\text { dikelompokkan sebagai transaksi sewa } \\
\text { menyewa biasa (operating lease). }\end{array}$ \\
\hline
\end{tabular}

Dari tabel di atas terlihat bahwa pada PSAK No. $30 \quad$ (Revisi 2007) pengklasifikasian sewa sebagai sewa pembiayaan atau sewa operasi didasarkan pada substansi transaksi dan bukan pada bentuk kontraknya (principle based vs rule based).

\subsection{Penelitian Pasar Modal dan Relevansi Nilai}

Seperti yang dinyatakan Darwin (2008), penelitian pasar modal sekarang ini telah memperlihatkan bahwa laporan akuntansi memiliki kandungan informasi, dan angka-angka yang tercantum dalam laporan keuangan tersebut mencerminkan informasi yang dapat mempengaruhi harga sekuritas. Kothari (2000) dalam Darwin (2008) telah membagi demand atas penelitian pasar modal ini menjadi lima area utama, yaitu: (1) riset metodologikal pasar modal; (2) evaluasi alternatif pengukuran kinerja akuntansi; (3) valuasi dan riset terhadap analisa fundamental; (4) pengujian efisiensi pasar, dan (5) relevansi nilai dari pengungkapan (disclosure) 
berdasarkan berbagai standar akuntansi keuangan dan konsekuensi ekonomis dari penerapan standar akuntansi yang baru.

Penelitian mengenai relevansi nilai umumnya menguji asosiasi harga sekuritas sebagai variabel bebas dengan serangkaian variabel akuntansi. Secara umum suatu angka akuntansi disebut memiliki relevansi nilai jika angka tersebut secara signifikan berkaitan dengan nilai pasar ekuitas (Darwin, 2008).

Penelitian yang menguji relevansi nilai dari pengungkapan juga telah banyak dilakukan (Botosan, 1997; Gulo, 2000; Aditomo, 2009). Namun penelitian tersebut masih menunjukkan hasil yang beragam. Botosan (1997) dengan indeks pengungkapannya tidak berhasil menemukan hubungan antara tingkat pengungkapan dengan cost of equity capital, hasil yang serupa juga ditemukan oleh Gulo (2000). Sedangkan Aditomo (2009) berhasil menemukan bahwa pengungkapan CSR berpengaruh positif terhada nilai perusahaan.

\subsection{Peningkatan Relevansi Nilai PSAK No. 30 (Revisi 2007)}

Cheng, Liu and Schaefer pada tahun 1997 telah melakukan penelitian yang menguji peningkatan relevansi nilai atas suatu standar akuntansi keuangan yang baru. Dalam penelitiannya ini Cheng, Liu and Schaefer (1997) menguji relevansi nilai dari SFAS No. 95, yaitu tentang kewajiban pelaporan Laporan Arus Kas dari aktivitas operasi menggunakan format yang terstandarisasi (sebelumnya perusahaan di Amerika tidak wajib menyajikan Laporan Arus Kas). Dan setelah melakukan kontrol atas informasi laba, ternyata hasil penelitian menunjukkan pasar menilai Laporan Arus Kas dari aktivitas operasi memiliki relevansi nilai bagi pengambilan keputusan investasi.

Dalam PSAK No. 30 (Revisi 2007), pengungkapan mengenai aktivitas sewa didasarkan pada substansi transaksi dan bukan pada bentuk kontraknya (principle based vs rule based), sehingga tidak akan ada lagi aset dan kewajiban (yang timbul dari perjanjian sewa atau mengandung sewa) yang bersifat off-balance sheet. Terkait dengan kelebihan PSAK No. 30 (Revisi 2007) ini, maka diharapkan pasar akan bereaksi positif. Oleh karenanya dalam penelitian ini dirumuskan hipotesis dalam format alternatif sebagai berikut:

H$_{1}$ : PSAK No. 30 (Revisi 2007) memiliki relevansi nilai.

\section{METODOLOGI PENELITIAN}

\subsection{Model Empiris dan Variabel Penelitian}


Penelitian ini mengacu pada penelitian yang dilakukan oleh Cheng, Liu and Schaefer (1997), namun dilakukan beberapa modifikasi agar sesuai dengan tujuan penelitian. Untuk menguji peningkatan hubungan antara return saham dan PSAK No. 30 (Revisi 2007), serta melakukan kontrol atas informasi laba, maka guna menguji hipotesis yang diajukan kami menggunakan model regresi sebagai berikut:

$$
\begin{aligned}
C A R_{j t}=\propto_{0}+ & \propto_{1} \Delta E_{j}+\propto_{2}\left(\frac{E_{j}}{E Q_{j}}\right) \\
& +\propto_{3} \Delta A S P_{j}+\varepsilon_{j}
\end{aligned}
$$

Dimana:

$C A R_{j t}$ : Cumulative abnormal return untuk perusahaan $j$ pada tanggal $t$.

$E_{j} \quad$ : laba untuk perusahaan $j$ pada laporan keuangan tahun 2008.

Dimana $\Delta E_{j}$ adalah proporsi perubahan nilai laba dari tahun 2007 ke tahun 2008.

$E Q_{j} \quad$ : Nilai buku ekuitas perusahaan $j$ pada awal tahun 2008.

$\triangle A S P$ : proporsi perubahan jumlah aset sewa pembiayaan dari tahun 2007ke tahun 2008.

\subsection{Pengukuran Variabel}

3.2.1. Variabel Dependen (Cumulative Abnormal Return - CAR $)$
Dalam menguji relevansi nilai dari SFAS 13, Cheng dan Hsieh (2000) menggunakan data return perusahaan selama sembilan bulan sebelum dan tiga bulan sesudah akhir tahun buku saat SFAS 13 mulai diadopsi. Dalam penelitian ini, peneliti menghitung nilai $C A R$ dengan periode estimasi selama enam bulan (tiga bulan sebelum dan tiga bulan sesudah tanggal 31 Maret 2009). Dipilihnya tanggal ini sebagai cut-off, karena tanggal 31 Maret adalah tanggal terakhir perusahaan harus memberikan laporan keuangan tahunan ke BAPEPAM dan juga untuk mempermudah perhitungan. CAR dirumuskan sebagai berikut.

$$
\begin{aligned}
& \mathrm{CAR}_{\mathrm{it}}=\mathrm{CAR}_{\mathrm{i}(-60,+60)}=\sum_{\mathrm{t}=-60}^{+60} \mathrm{AR}_{\mathrm{it}} \\
& \mathrm{AR}_{\mathrm{it}}=\mathrm{R}_{\mathrm{it}}-\mathrm{E}\left(\mathrm{R}_{\mathrm{it}}\right) \\
& \mathrm{R}_{\mathrm{it}}=\frac{\mathrm{P}_{\mathrm{it}}-\mathrm{P}_{\mathrm{it}-1}}{\mathrm{P}_{\mathrm{it}-1}} \\
& \mathrm{E}\left(\mathrm{R}_{\mathrm{it}}\right)=\alpha_{\mathrm{i}}+\beta_{\mathrm{i}} \mathrm{R}_{\mathrm{Mt}} \\
& \mathrm{R}_{\mathrm{Mt}}=\frac{\mathbb{H S G}_{\mathrm{t}}-\mathbb{H S G}_{\mathrm{t}-1}}{\mathbb{H S G}_{\mathrm{t}-1}}
\end{aligned}
$$

Dimana:

$\mathrm{AR}_{\text {it }}$ :abnormal return perusahaan i pada hari t

$\mathrm{R}_{\mathrm{it}}$ :actual return perusahaan $\mathrm{i}$ pada hari t

$\mathrm{R}_{\mathrm{Mt}} \quad$ :return pasar pada hari $\mathrm{t}$

$\mathrm{P}_{\text {it }} \quad$ : closing price saham perusahaan i pada hari $\mathrm{t}$

$\mathrm{P}_{\mathrm{it}-1} \quad$ :closing price saham perusahaan i pada hari sebelum $\mathrm{t}$ 
$\mathrm{E}\left(\mathrm{R}_{\mathrm{it}}\right)$ :expected return saham perusahaan $\mathrm{i}$ pada hari $\mathrm{t}$

$\alpha_{\mathrm{i}} \quad$ :intercept untuk saham perusahaan i

$I_{H S G}$ : indeks harga saham gabungan pada hari $t$

IHSG $_{\mathrm{t}-1}$ : indeks harga saham gabungan pada hari sebelum $t$

\subsubsection{Variabel Independen}

Dalam penelitian ini variabel $\triangle A S P$ menotasikan proporsi perubahan jumlah aset sewa pembiayaan akibat adanya PSAK No. 30 (Revisi 2007). Cheng dan Hsieh (2000) menyatakan bahwa efek dari suatu perubahan dapat dilihat dari perubahan besaran suatu variabel, atau proporsi perubahan besaran suatu variabel. Dalam penelitian ini kami mengukur perubahan proporsi nilai aset sewa pembiayaan yang dimiliki perusahaan dengan cara mengurangi nilai aset sewa pembiayaan yang dimiliki perusahaan pada tahun 2008 dikurangi dengan nilai aset sewa pembiayaan yang dimiliki perusahaan pada tahun 2007, kemudian membaginya dengan nilai aset sewa pembiayaan yang dimiliki perusahaan pada tahun 2007.

\subsubsection{Variabel Kontrol}

Brown dkk. (1987) dalam Cheng, Liu and Schaefer (1997) menunjukkan bahwa penggunaan banyak proksi akan lebih baik daripada hanya menggunakan satu proksi, karena hal ini akan mengurangi kemungkinan adanya kesalahan pengukuran. Oleh karenanya ,sama seperti yang dilakukan juga oleh Cheng, Liu and Schaefer (1997), dalam penelitian ini relevansi nilai dari laba akan diukur dengan menjumlahkan koefisien perubahan dan tingkat laba $\left(\propto_{1}+\propto_{2}\right)$.

\subsection{Sampel dan Data}

Sampel yang digunakan dalam penelitian ini mencakup perusahaan manufaktur yang terdaftar di Bursa Efek Indonesia untuk periode tahun 2008-2009. Data yang diambil berasal dari laporan keuangan tahun 2008 dan data OSIRIS. Alasan diambilnya data laporan keuangan pada satu periode tersebut karena PSAK No. 30 (Revisi 2007) baru efektif pada tanggal 1 Januari 2008. Sehingga pengungkapannya baru terlihat di laporan keuangan tahun 2008.

\subsection{Pengolahan Data dan Pengujian Hipotesis}

Data akan diolah dengan bantuan program Eviews dan model akan diestimasi dengan menggunakan regresi OLS. Sebelum dilakukan pengujian hipotesis akan dilakukan uji asumsi klasik untuk melihat apakah data terdistribusi 
secara normal, tidak terjadi heteroskedastisitas, dan tidak terjadi multicollinearity.

\section{ANALISIS HASIL PENELITIAN}

\subsection{Gambaran Umum Sampel}

\section{Penelitian}

Sampel yang digunakan dalam penelitian ini adalah seluruh perusahaan manufaktur yang terdaftar pada BEI pada tahun 2008 dan 2009. Detil nama perusahaan didapat dari ICMD 2008, sedangkan data keuangan perusahaan didapat dari website BEI, www.idx.co.id per tanggal 21 Agustus 2009.

Total perusahaan dalam populasi berjumlah 151 perusahaan, namun ada 29 perusahaan yang pada tanggal 21 Agustus 2009 laporan keuangan tahunannya tidak ada di website BEI, oleh karenanya hanya 122 perusahaan yang akan diuji apakah memenuhi kriteria sampel. Agar mudah untuk dianalisis, maka perusahaan yang melaporkan dalam kurs moneter selain rupiah akan dikeluarkan dari sampel (4 perusahaan). Perusahaan yang tidak memiliki aset sewa pembiayaan juga dikeluarkan dari sampel (68 perusahaan). Agar dapat diperbandingkan, perusahaan yang akan dianalisis harus mempunyai akhir tahun buku per tanggal 31 Desember (ada satu perusahaan yang tidak memenuhi kriteria tersebut). Perusahaan yang masing menggunakan standar akuntansi sewa yang lama (PSAK No. 30 Tahun 1990) akan dikeluarkan dari sampel (6 perusahaan). Sedangkan untuk menghindari bias serta mempermudah interpretasi, maka perusahaan yang dalam masa observasi terdapat penerapan standar akuntansi baru lainnya (4 perusahaan), atau terdapat mutasi aset sewa pembiayaan karena masa sewa telah berakhir (4 perusahaan) juga akan dikeluarkan dari sampel. Agar model pengujian dapat dijalankan, maka perusahaan dengan data return yang tidak lengkap (lebih dari 30 data harian) akan dikeluarkan dari sampel (5 perusahaan). Rangkuman pemilihan sampel yang digunakan dalam penelitian dapat dilihat dalam Tabel 4.1. 
Tabel 4.1

Tabel Pemilihan Sampel Penelitian

\begin{tabular}{|c|c|c|}
\hline $\begin{array}{l}\text { Sampel awal } \\
\text { Keterangan }\end{array}$ & $\begin{array}{r}\text { Jumlah } \\
\text { perusaha }\end{array}$ & \\
\hline Perusahaan manufaktur & & 151 \\
\hline \multicolumn{3}{|l|}{ Dikurangi kriteria sampel } \\
\hline a. Laporan keuangan tidak ada dalam website BEI & 28 & \\
\hline b. Laporan keuangan dalam non-rupiah & 4 & \\
\hline c. Tidak memiliki aset sewa pembiayaan & 68 & \\
\hline d. Akhir tahun buku bukan per tanggal 31 Desember & 1 & \\
\hline e. Menerapkan PSAK 30 (1990) & 6 & \\
\hline $\begin{array}{l}\text { f. Pada masa observasi, terdapat penerapan SAK baru } \\
\text { lainnya }\end{array}$ & 4 & \\
\hline g. Mutasi aset sewa pembiayaan & 4 & \\
\hline $\begin{array}{l}\text { h. Data return tidak lengkap (lebih dari } 30 \text { data harian) } \\
\text { Sampel final }\end{array}$ & $\underline{5}$ & $\frac{120}{31}$ \\
\hline
\end{tabular}

Data return harian perusahaan didapat dari OSIRIS, yang diunduh pada tanggal 21 Oktober 2009.

\subsection{Analisis Statistik Deskriptif}

Suatu statistik deskriptif bertujuan untuk memberikan gambaran sederhana mengenai data dan hasil dari penelitian yang dilakukan (Agung, 2001).

Tabel 4.2

Statistik Deskriptif Selama Periode Observasi

\begin{tabular}{lccccc}
\hline \multicolumn{1}{l}{ Mean } & Median & Min & Maks. & Std. Dev. \\
\hline $\begin{array}{l}\text { Variabel } \\
\text { CAR }\end{array}$ & & & & & \\
$\Delta E$ & 0.04 & -0.07 & -0.72 & 1,06 & 0,43 \\
$E$ & $-0,63$ & 0,10 & $-11,03$ & 3,51 & 2,83 \\
$\Delta A S P$ & 0,26 & 0,07 & $-0,52$ & 2,82 & 0,59 \\
\hline
\end{tabular}

Sumber: Data diolah

Dari Tabel 4.2 terlihat bahwa perusahaan yang digunakan dalam penelitian tersebar dari perusahaan yang memiliki laba negatif sampai yang kinerjanya baik, hal ini terlihat dari nilai $\triangle E$ dan E. Nilai $C A R$ berkisar dari -0,72 sampai 1,06 juga menunjukkan bervariasinya perusahaan sampel. Dari analisis data diketahui banyak saham perusahaan sampel yang sifatnya saham 
tidur, jarang diperdagangkan. Nilai mean $\triangle A S P$ sebesar 0,72 menunjukkan adanya ratarata peningkatan aset sewa pembiayaan yang dimiliki perusahaan.

\subsection{Uji Asumsi Klasik}

\subsubsection{Uji Multikolinieritas}

Dengan menggunakan pair-wise correlation, hubungan antara variabel yang diuji tidak ada yang lebih dari 0,5. Nilai VIF (TOL) variabel bebas yang diuji juga kebanyakan nilainya di bawah nilai 2 (mendekati nilai 1). Sehingga disimpulkan tidak terjadi masalah multikolinieritas (lihat Tabel 4.3).

\subsubsection{Uji Heteroskedastisitas}

Dengan menggunakan uji White, diketahui nilai prob. Menunjukkan nilai 0,73 , sehingga hipotesis yang menyatakan terdapat heteroskedastisitas ditolak (tidak terdapat masalah heteroskedastisitas).

\subsubsection{Uji Normalitas}

Untuk memastikan bahwa data berdistribusi normal, maka penelitian ini melakukan uji normalitas. Karena pengujian dalam penelitian ini menggunakan software EViews, maka uji normalitas dilakukan dengan melakukan uji Jarque-Bera.

Dari Winarno (2009) diketahui bahwa suatu data dinyatakan berdistribusi normal jika memiliki nilai koefisien Jarque Bera lebih kecil dari 2, dan nilai probability lebih besar dari 5\%. Karena hasil uji Jarque Bera dalam penelitian ini menunjukkan koefisien Jarque Bera sebesar 0,918 (prob. 0,632), maka dapat disimpulkan data dalam penelitian ini berdistribusi normal.

\subsection{Uji Hipotesis}

Hasil regresi model empiris dapat dilihat pada Tabel 4.3. Berdasarkan tabel tersebut, model regresi yang digunakan dapat ditulis sebagai berikut:

$$
\begin{aligned}
C A R_{j t}=0,025 & -0,059 \Delta E_{j} \\
& +0,082\left(\frac{E_{j}}{E Q_{j}}\right) \\
& -0,060 \Delta A S P_{j}+\varepsilon_{j}
\end{aligned}
$$

\begin{tabular}{|c|c|c|c|c|c|}
\hline Variabel & Koefisien & t-statistic & Prob. & TOL & $V I F$ \\
\hline$C$ & 0,025 & 0.266480 & 0.7919 & & \\
\hline$\Delta E_{j}$ & $-0,059$ & -2.160163 & 0.0398 & ,856 & 1,168 \\
\hline$E_{j}$ & 0,082 & 0.620036 & 0.5404 & 983 & 1,018 \\
\hline
\end{tabular}

Tabel 4.3

Hasil Regresi Model Empiris 


\begin{tabular}{|c|c|c|c|c|c|}
\hline$\triangle A S P_{\mathrm{j}}$ & $-0,060$ & -0.969187 & 0.3411 & ,849 & 1,178 \\
\hline \multicolumn{6}{|c|}{ Adjusted R-squared : 0,874} \\
\hline \multicolumn{6}{|c|}{ F-statistic $\quad: 3,687$} \\
\hline \multicolumn{6}{|c|}{$\operatorname{Prob}(F$-statistic $) \quad: 0,002$} \\
\hline \multicolumn{6}{|c|}{$\begin{array}{l}\Delta E_{j}=\text { proporsi perubahan laba perusahaan } j, E_{j}=\text { laba perusahaan } j, \Delta A S P_{j}=\text { proporsi } \\
\text { perubahan aset sewa pembiayaan perusahaan } j \text {. }\end{array}$} \\
\hline
\end{tabular}

Dalam Tabel 4.3 diketahui bahwa nilai $F$-statistic persamaan di atas memiliki $\operatorname{Prob}(F$-statistic) sebesar 0,055, hal ini menunjukkan bahwa variabel-variabel bebas yang diuji secara bersama-sama signifikan $(\alpha=10 \%)$ mempengaruhi variabel terikat $(C A R)$. Besaran adjusted $R$ squared menunjukkan nilai 0,157 , artinya besaran $C A R$ dapat dijelaskan oleh $\triangle E, E$, dan $\triangle A S P$ sebesar $15,7 \%$. Sisanya sebanyak $84,3 \%$ dijelaskan oleh variabel lain yang tidak dibahas dalam penelitian ini.

Penjumlahan koefisien $\alpha_{1}$ dan $\alpha_{2}$ $(0,023)$ merupakan notasi dari inkremental nilai laba. Nilai inkremental

\subsection{Pembahasan Hasil Penelitian}

Nilai koefisien estimasi regresi variabel $\triangle A S P$ yang menunjukkan nilai positif namun tidak signifikan, mengindikasikan bahwa penelitian ini tidak mampu memberikan bukti adanya hubungan antara pengaruh diterapkannya nilai laba yang positif ini sesuai dengan penelitian-penelitian sebelumnya yang menunjukkan adanya hubungan positif antara kandungan informasi dari laba yang mempengaruhi return perusahaan (lihat Cheng, Liu and Schaefer (1997), dan Cheng dan Hsieh (2000)). Koefisien estimasi regresi variabel $\triangle A S P$ yang menunjukkan prob.0,341, menunjukkan bahwa perubahan jumlah aset sewa pembiayaan yang dimiliki perusahaan tidak mempunyai pengaruh kepada return perusahaan. Dengan demikian dugaan hipotesis $1\left(\mathrm{H}_{1}\right)$ yang menyatakan bahwa PSAK No. 30 (Revisi 2007) memiliki relevasi nilai tidak terbukti (ditolak).

PSAK No. 30 (Revisi 2007) dengan return perusahaan. Atau bisa dikatakan pasar tidak bereaksi dengan adanya PSAK No. 30 (Revisi 2007) ini, sehingga dianggap PSAK No. 30 (Revisi 2007) tidak memiliki relevansi nilai. Dari analisis data, alasan yang mungkin dapat menjelaskan mengapa hal ini terjadi adalah karena bagi 
banyak perusahaan perubahan pengakuan aset sewa ini tidak bersifat material. Kebanyakan perusahaan mengimplementasikan PSAK ini secara prospektif, tidak dilakukan penyesuaian atas pengakuan aset sewa periode sebelum tanggal 1 Januari 2008. Dan pasar tidak melihatnya sebagai suatu hal yang krusial.

\section{KESIMPULAN DAN KETERBATASAN PENELITIAN}

\subsection{Kesimpulan Penelitian}

Penelitian ini bertujuan untuk menguji apakah PSAK No. 30 (Revisi 2007) memiliki relevansi nilai. Suatu standar dikatakan memiliki relevansi nilai jika pasar bereaksi terhadapnya. Pengujian dilakukan terhadap perusahaan manufaktur yang terdaftar di Bursa Efek Indonesia untuk periode 2008 - 2009, yang memenuhi kriteria sampel. Sedangkan data return perusahaan didapat dari OSIRIS.

Setelah melakukan kontrol terhadap nilai laba buku, hasil uji regresi menunjukkan bahwa penelitian ini belum mampu memberikan bukti atas $\mathrm{H}_{1}$ yang menyatakan bahwa PSAK No. 30 (Revisi 2007) memiliki relevansi nilai. Diduga alasan yang menyebabkan hal ini terjadi adalah karena perubahan cara pengakuan aset sewa pembiayaan ini tidak berpengaruh secara material kepada perusahaan. Hal ini terlihat dari kebijakan perusahaan yang menerapkan peraturan ini secara prospektif, dimana dianggap tidak perlu melakukan penyajian kembali atas laporan keuangan yang telah dilaporkan di periode sebelum tanggal 1 Januari 2008.

\subsection{Keterbatasan Penelitian}

Terdapat beberapa keterbatasan yang ditemui dalam penelitian ini. Pertama, karena sepengetahuan penulis penelitian semacam ini belum pernah dilakukan di Indonesia, maka model maupun kriteria sampel penelitian belum teruji kehandalannya. Kedua, perusahaan yang digunakan sebagai sampel dalam penelitian ini jumlahnya sangat sedikit dan hanya perusahaan manufaktur. Sehingga hasil penelitian ini tidak dapat digeneralisir.

\subsection{Saran Untuk Penelitian}

\section{Selanjutnya}

Dengan berbagai keterbatasan yang terdapat dalam penelitian ini, maka dapat direkomendasikan beberapa hal berikut. Pertama, agar model pengujian teruji kehandalannya, sebaiknya dilakukan uji robustness dengan menggunakan variabel lain. Kedua, melakukan pengujian kepada berbagai jenis industri dengan periode observasi yang lebih panjang. 
Agar hasil penelitian bisa diterima oleh umum.

\section{DAFTAR PUSTAKA}

Aditomo, D. Pengaruh pengungkapan corporate social responsibility, kepemilikan keluarga, dan kepemilikan asing terhadap nilai perusahaan (studi empiris pada perusahaan publik yang tercatat di Bursa Efek Indonesia pada tahun 2008). Tesis Program Studi Ilmu Akuntansi Program Magister Akuntansi Fakultas Ekonomi Universitas Indonesia, 2009.

Agung, I Gusti Ngurah (2001). Statistika, Analisis Hubungan Kausal Berdasarkan Data Kategorik. Jakarta: PT RajaGrafindo Persada.

Botosan, C. A. (1997). Disclosure Level and the Cost of Equity Capital. The Accounting Review, 72 (3), 323-349.

Brown, L., P. Griffin, R Hagerman, and M. Zmijewski. (1987). An evaluation of alternative proxies for the market's assessment of unexpected earnings. Journal of Accounting and Economics, 2 (July), 159-194.

Cheng, C. S. A., Chao-Shin Liu, \& Schaefer, T. F. (1997). The Value-Relevance of SFAS No. 95 Cash Flows from Operations as Assessed by Security Market Effects. Accounting Horizons, 11 (3), 1-15.

Darwin, W. Relevansi nilai informasi akuntansi terhadap penentuan nilai pasar perusahaan periode 1992-2005: Studi empiris pada Bursa Efek Jakarta. Tesis Program Studi Ilmu Akuntansi Program Magister Akuntansi Fakultas Ekonomi Universitas Indonesia, 2008.

Gulo, Y. (2000). Analisis efek luas pengungkapan sukarela dalam laporan tahunan terhadap cost of equity capital perusahaan. Jurnal Bisnis dan Akuntansi, 2 (1), 45-62.

Jamal, K. and Tan Hun-Tong (2009). Effect of Principles-based versus Rules-based Standards and Auditor Type on Financial Managers' Reporting Judgements.www.ssrn.com

Nugrahanti, Y. W. (2006). Hubungan antara Luas Ungkapan Sukarela dalam Laporan Tahunan. Jurnal Ekonomi dan Bisnis. XII (2), 152-171.

Sinaga, R. U. (2009, Oktober). Strategi adaptasi IFRS. Artikel dipresentasikan di Seminar Konvergensi IFRS dan Workshop Penerapan PSAK Terbaru. Depok, Indonesia.

Standar Akuntansi Keuangan. (2009). Jakarta: Penerbit Salemba Empat. 
Tsakumis, G. T., Doupnik, T. S. \& Agoglia, C. P. (2009). Principles-based versus Rulesbased Accounting Standards: The Influence of Standard Precision and Audit Committee Strength on Financial Reporting Decisions. www.ssrn.com

Wihardja, R. I. (10 Mei 2009). PSAK 30 Revisi 2007 Sulit Disosialisasikan. http://www.detikfinance.com/read/2009/05/10/162015/1129068/4/psak-30-revisi2007-sulit-disosialisasikan. 